Stoa

Vol. 9 , no. 17,2018 , pp. $47-67$

ISSN 2007-1868

\title{
LA HISTORIA: LA ANTIMEMORIA DE LA MEMORIA "HISTÓRICA”
}

\author{
Jesús Turiso Sebastián \\ Instituto de Filosofía \\ Universidad Veracruzana \\ jturiso@uv.mx
}

RESUMEN: En los últimos tiempos estamos asistiendo al surgimiento o resurgimiento de la preocupación por el rescate de la Memoria Histórica y, esta preocupación, se está viendo también en la atención dispensada por destacados historiadores. Los medios de comunicación la han puesto como tema de moda y, de esta manera, están impulsado la aparición de una conciencia histórica nueva en nuestras sociedades, que exigen una respuesta a los historiadores para satisfacer los interrogantes de nuestro presente con respecto al pasado. El planteamiento que pretendo llevar a cabo pasa por mostrar de qué manera la historia investigada y estudiada científicamente se convierte en la propia destrucción de la memoria histórica y de su escritura.

PAlABRAS ClAVE: Memoria · memoria histórica $\cdot$ Antimemorias

ABSTRACT: We are witnessing in recent times the emergence or resurgence of concern for the rescue of Historical Memory and, this concern, it is also seen in the attention given by prominent historians. The media have put this as a fashionable theme and in this way the emergence of a new historical consciousness in our societies, which demand a response to the historians to satisfy the questions of our present with respect to the past. The approach I intend to take is to show how the history researched and studied scientifically becomes the very destruction of historical memory and its writing.

KEYWORDS: History $\cdot$ Historical Memory $\cdot$ Antimemory 
El culto a la memoria no siempre sirve a la justicia; tampoco es forzosamente favorable para la propia memoria.

Tzventan Todorov

\section{Introducción}

Nuestro presente no es sólo la época de la historia que en la que más conciencia histórica se tiene y, por ende, la época en la que más se piensa en términos históricos, sino que además es el período en el que más se está utilizando a la historia para justificar o deslegitimar situaciones, hechos, e incluso, procesos que se están dando en el presente. Por otro lado, las demandas sociales que exigen entender las vertiginosas transformaciones que están sucediendo sitúan a la historia y a los historiadores en el punto de mira de las explicaciones que permitan comprender nuestro mundo cambiante. La posibilidad del presente como estudio histórico que hasta no hace mucho estaba seriamente cuestionado por gran parte de la comunidad historiográfica, por efecto de los requerimientos de estas sociedades actuales para responder a los interrogantes de nuestro presente con respecto al pasado, se está convirtiendo en uno de los temas estrellas de las líneas de investigación de algunos destacados historiadores.

En la búsqueda de respuestas, nuestro presente ha recurrido a la memoria, o mejor dicho, a las memorias históricas recuperadas del pasado cercano para dar sentido y legitimidad a situaciones que acontecen en el presente. Es de esta manera cómo la preocupación por el rescate de la memoria histórica ${ }^{1}$ está llevando a la historia actual a centrar su atención en ese sentido.

En muchos países en los que en el pasado reciente han experimentado tragedias sociales - guerras, dictaduras, persecuciones, limpiezas étnicas, etc.- el recuerdo de las víctimas y la recuperación de su memoria se ha convertido en uno de los temas importantes, y en algunos casos urgentes, de sus agendas políticas.

\footnotetext{
${ }^{1}$ A lo largo del artículo se empleará el término de memoria "histórica" entrecomillado, por entender que la memoria no tiente que ver más con la historia que, por ejemplo, la biología o las matemáticas, y no es fruto de la historia entendida como ciencia, por lo que en muchas ocasiones recurriré al sinónimo de memoria colectiva, el cual me parece más oportuno.
} 
Pues bien, partiendo de aquí, se pretende mostrar cómo memoria e historia son cosas distintas. El planteamiento que pretendo llevar a cabo pasa por mostrar de qué manera la historia analizada y estudiada científicamente se convierte en la propia antimemoria de la memoria "histórica" o memoria colectiva y de su escritura. Esto, desde el punto de vista operativo, no significa que la memoria tenga que desaparecer o invalidarse como realidad social, sino simplemente lo que se destaca es que son realidades que operan a través de registros diferentes.

Un primer momento de este trabajo se centrará en exponer en qué consiste el presente como historia, qué se entiende por memoria y qué relación se establece entre memoria e historia. Seguidamente, se va a partir del hecho de que memoria e historia son cosas opuestas, ya que la memoria se sostiene con el recuerdo o la voluntad de recordar, mientras que la historia se construye con documentos y se sitúa en el plano del entendimiento. En un tercer momento se ejemplarizará la construcción de la memoria desde el poder. Finalmente, expondré cómo, a partir del rigor epistemológico y metodológico, la historia se constituye en destructora de la memoria.

\section{El presente, la historia y la memoria}

Si partimos de la definición del maestro Marc Bloch de que la historia es la ciencia de los hombres en el tiempo, ${ }^{2}$ la historia sería la ciencia que se dedica al examen crítico centrado en el estudio tanto del pasado como del presente. Y para entender nuestro presente es necesario recurrir al pasado, ya que una de las razones que limitan la comprensión del presente se origina en el desconocimiento del pasado. No por nada Benedetto Croce ya sostuvo en el siglo xix que la historia es siempre contemporánea, dado que la historia siempre se escribe teniendo como referente las circunstancias del presente. Y, ahí es donde entra en liza la memoria, porque la memoria colectiva se construye justamente desde los distintos presentes de la historia. Memoria e historia difieren en cómo reconstruyen el pasado.

$\mathrm{Al}$ iniciar esta reflexión habría que empezar por distinguir entre las memorias individuales o familiares y las narrativas oficiales referentes

${ }^{2}$ Vid. Bloch, M., 2001, Apología de la historia o el oficio de historiador, México, Fondo de Cultura Económica, p. 58. 
a la memoria o que pretender elaborar una memoria colectiva. En el primer caso, para abordar la relación entre presente y memoria partiré de la idea del presente como tiempo de la experiencia vivida. En el sentido histórico, asocio esa experiencia vivida no sólo con la experiencia propia de nuestra generación actual, sino también con la experiencia vivida de nuestros mayores quienes, a través de la memoria o el recuerdo, han compartido con nuestra generación el pasado del que fueron actores o testigos pero que nosotros no hemos vivido. Por lo tanto, nosotros no sólo somos nuestro presente y nuestros recuerdos, sino también la memoria de la experiencia vivida de nuestros predecesores. Un ejemplo: de la tragedia de la Guerra Civil española y su posguerra no fui testigo presencial, sin embargo, los recuerdos relatados de mis padres pasan a formar parte de mi presente y se han convertido en experiencia vivida propia a través de su memoria. De esta forma, la tragedia de la guerra que vivió España está todavía tan viva en la memoria de los españoles, que sistemáticamente intentamos comprender nuestro presente a través de este pasado reciente. Hasta tal punto ha sido así, que la sociedad actual demanda a sus representantes políticos que se desentrañe el conocimiento de esa época. Desde el 2007 el Estado español -y aquí es donde entran la elaboración de narrativas oficiales- se ha visto involucrado en el rescate de la memoria "histórica" de ese periodo de la historia de España y, como antes se hizo en Francia o Alemania, su parlamento aprobó la Ley de Memoria Histórica. Dicha ley ha supuesto un intento, no me atrevería afirmar que exitoso, de satisfacer el reconocimiento de todas las víctimas de la Guerra Civil Española y de la dictadura franquista. ${ }^{3}$ Esto ha planteado una ardua discusión entre historiadores acerca del concepto historiográfico, pero también ideológico, de memoria histórica y esto es así porque el interés en el pasado reside en la comprensión del presente. El problema de fondo es que la memoria del pasado, al ser siempre una reconstrucción, corre el riesgo de verse acometida por corrientes ideológicas, intereses políticos o líneas interpretativas de escuelas historiográficas, dejando de ser lo que la historia para muchos debe ser: solamente historia. Sin embargo, el pasado no se puede cambiar, no

${ }^{3}$ Vid. Agencia Estatal. Boletín Oficial del Estado (27 de diciembre de 2007). "Ley 52/2007, de 26 de diciembre, por la que se reconocen y amplían derechos y se establecen medidas en favor de quienes padecieron persecución o violencia durante la guerra civil y la dictadura". 
es ya una realidad material que se pueda transformar a posteriori, es simplemente pasado. Ahora bien, las acciones que se llevan a cabo en el presente pueden estar influidas o mediatizadas por las experiencias del pasado, lo cual genera controversias sobre la reconstrucción de la historia. Bien decía el maestro Lucien Febvre que "el hombre no se acuerda del pasado, lo reconstruye. El hombre aislado es una abstracción. La realidad es el hombre en grupo. Y el hombre no conserva en su memoria el pasado de la misma forma en que los hielos del Norte conservan congelados los mamuts milenarios. Arranca del presente y a través de él, siempre, conoce e interpreta el pasado". ${ }^{4}$ Ciertamente, el pasado se interpreta a través del presente, con todo lo que entraña esto: nuestros prejuicios, nuestras categorías y, como no, nuestra moral. El historiador no debe juzgar la moralidad de los hechos, debe analizarlos con fundamentos críticos que le ofrecen las herramientas metodológicas de la historia. Sin embargo, esto no ha sido óbice para que se reflexione sobre los usos morales de la historia en relación con la memoria, el negacionismo y la identidad cultural. Sartre (1948) recurre a la vindicación de la memoria de la shoa de los judíos frente al antisemitismo desde un diálogo con el presente porque "Su memoria colectiva sólo les procura oscuros recuerdos de pogromos, de ghettos, de éxodos, de grandes sufrimientos monótonos, veinte siglos de repetición, no de evolución. El judío no es aún histórico y sin embargo es, o casi, el más antiguo de los pueblos: lo cual le da ese aire perpetuamente envejecido y siempre nuevo; tiene una sabiduría y no tiene historia" (pp. 78-79). Todorov (1993), por su parte, establece la diferencia clara entre la actitud crítica y el negacionismo y la sitúa en que la actitud de los negadores "[...] se vale del porvenir o del pasado para condenar el presente, mientras que la primera se refiere a los principios constitutivos de la sociedad del presente, en este caso a los principios democráticos, para criticar su realización imperfecta en la vida de cada día” (p. 270). Vemos cómo las memorias del pasado reciente todavía están plenamente en consonancia con el presente, básicamente porque este proceso histórico del pasado reciente todavía no está concluso, y no lo hará hasta que sus implicaciones con el presente estén totalmente cerradas.

${ }^{4}$ Cfr. Febvre, L., 1982, Combates por la historia, Seix Barral, Barcelona, p. 32. 
Cuando el pasado es lejano, la reconstrucción que se hace de él no tiene tantas implicaciones políticas o sociales para nuestro presente. Que César cruzara el Rubicón o no, o que existiera un complot para asesinar con pequeñas dosis de arsénico a Napoleón durante años en la Isla de Santa Elena o muriese simplemente de manera natural, realmente no es algo que interese a nuestras sociedades ni tenga trascendencia en ellas más allá de lo puramente especulativo o, incluso, novelesco. Sin embargo, lo que sí genera mucha polémica es la reconstrucción de la memoria del pasado reciente y ello se debe fundamentalmente a que muchos de sus actores y testigos todavía están presentes y pueden relatarlo. Otro problema añadido es que a veces todavía sobreviven historiadores que fueron también testigos de los acontecimientos que ahora investigan y escriben sobre su propia vida. Y, un último problema, sería las urgencias del poder político por construir narrativas del pasado que legitimen sus acciones del presente; es el caso de todas aquellas Historias nacionales y regionales, con tintes patrióticos o étnicos, escritas para dar legitimidad a una identidad. Esta comprometida situación ha hecho decir al historiador Javier Tussell que la reciente historia del presente es una historia en "libertad vigilada”. Asimismo, ha llevado a una parte importante de la comunidad historiográfica a poner en duda la posibilidad de estudiar nuestro presente desde la historia. Se pone en cuestionamiento y disputa, pues, el status ontológico de la historia e interpretativo de los profesionales de la historia. Nuestro problema como historiadores es que en ocasiones la realidad histórica que vamos descubriendo entra en conflicto con nuestras creencias y valores personales. Algunos historiadores pueden ser emocionalmente sensibles o insensibles a ciertos hechos, análisis o interpretaciones, lo cual no les permite la posibilidad de separar al observador de la cosa observada y a la Historia del historiador, que diría Paul Valery. Las exigencias institucionales y sociales ${ }^{5}$ por recuperar la memoria histórica pero desde la perspectiva ética de anteponer los valores de la democracia y la tolerancia al rigor histórico suponen una presión añadida a la tarea del historiador. Así, se puede observar, cómo

${ }^{5}$ Es lugar común la frase acuñada por el nacionalismo de "la historia es la memoria de los pueblo", o su variante más universal y lapidaria de "la historia es la memoria de los hombres". Pues bien, estos inocentes enunciados se transforman en armas ideológicas cuando se movilizan desde el poder y se les da un sentido adoctrinador. 
uno de las grandes dificultades de la neutralidad histórica es la manipulación sistemática de la historia en contextos políticos determinados - como sucede en la actualidad en Cataluña- donde se busca crear unas condiciones ideológico-culturales con el fin de posibilitar no sólo la imposición de una identidad, sino para conservar unas relaciones de poder y dominación. Recurrir al pasado en determinados contextos es especialmente conveniente, dado que permite generar las condiciones adecuadas de sensibilidad y conciencia necesaria para elaborar un clima identitario al que sumar más adeptos. Hacer una historia de los agravios es de por sí manipulador, porque la historia no es absoluta, la historia requiere de que se expliquen sus matices y realidades objetivas, necesarios para acercarnos lo más posible a la verdad histórica. Se recurre a la historia porque se entiende como un supuesto bálsamo legitimador, se trata pues de qué pasado es el adecuado, de qué pasado hay que tener: en México se ha construido la narrativa oficial que evoca en su historia a los héroes de la independencia y fustiga a los que considera como traidores. ${ }^{6}$ En este punto es donde estas exigencias éticas sobre el uso social de la historia entran en conflicto con el rigor que se supone debe tener la construcción científica del pasado, ya que la ética y la historia no necesariamente se comunican en el mismo lenguaje. Este escenario se explica porque a la historia se la ha atribuido importantes implicaciones sociales y políticas. Estas implicaciones están relacionadas con dictar una sentencia justa del pasado y decretar así quiénes fueron los buenos y quiénes los malos, quiénes fueron víctimas y quiénes verdugos. Estas funciones que se le exige al historiador, como dice Hobsbawm, "están en contradicción con sus criterios profesionales" (2004, p. 69) y el historiador no puede ni debe estar sometido a la tramposa dicotomía de escoger entre la verdad histórica y lo que políticamente correcto hay que considerar como verdad. La responsabilidad social con el presente del historiador reside precisamente en su compromiso con la verdad histórica, porque la historia no se sustenta

${ }^{6}$ En este sentido es paradójica la comparación de la figura del general Santa Anna (traidor) y la de Benito Juárez (héroe). Se considera un traidor Santa Anna por haber vendido más de la mitad del territorio mexicano a los EEUU, lo cual es una inexactitud histórica si no se tienen presentes los matices del proceso y las circunstancias del momento. En cambio, Benito Juárez es considerado el Benemérito de las Américas a pesar de que impulsó el tratado McLean-Ocampo por el cual vendía la soberanía de parte del territorio mexicano a los EE.UU. La suerte de Juárez fue que la Guerra de Secesión estadounidense obligó a suspender la firma en Congreso de los Estados Unidos y el tratado no se llevó a la práctica. 
en la memoria colectiva, sino en los historiadores profesionales. Y esto es así porque la memoria no es la historia.

\section{La memoria no es la historia}

Aunque la memoria es un elemento importante de la historia, no es necesariamente la historia. Una diferencia que me parece sustancial radica en que la memoria tiene un carácter acrítica, mientras que la historia es crítica. ${ }^{7} \mathrm{Si}$ bien ambas categorías remiten al pasado, son distintas y su campo de operación es también diferente. La memoria, elaborada desde la evocación personal, actúa en el ámbito del recuerdo fragmentario y relativo. La historia, sin embargo, es sistemática y opera en el esfera objetiva de la razón histórica materializada en documentos y otros materiales o utillaje históricos probatorios de los hechos examinados a través del método científico por la lupa del historiador, es decir, "con todo eso que, perteneciendo al hombre, sirve al hombre, expresa al hombre, demuestra la presencia, la actividad, los gustos y los modos de ser del hombre". ${ }^{8}$ Por tanto, la historia está sujeta al método y, por el contrario, la memoria se significa por su relativismo que obedece a la autoridad de la subjetividad personal de quien la elabora. El relativismo en la historia, si tiene aspiraciones de cientificidad, debe ser desterrado. Sin embargo, el relativismo caracterizador de la memoria colectiva no tiene que ser óbice para que el historiador no se preocupe y se ocupe de ella analizándola desde el rigor del método histórico, lo cual es necesario. No obstante, su estudio debe hacerse desde dos perspectivas: primero, la memoria tiene que ser analizada como fuente histórica; y, segundo, la memoria debe ser analizada como fenómeno histórico que elabora una serie de imágenes sociales para poder entender cómo se confecciona y quiénes son los que la van dando forma (Burke 2000, pp. 68-69).

Situando a cada cosa en su lugar, ya sabemos qué es la historia, pero todavía nos queda por deshilvanar el término memoria. Si buscamos

\footnotetext{
${ }^{7}$ La historia crítica es aquella que contempla tanto los tiempos pasados como el más actual presente, que se ocupa tanto de las permanencias como de los cambios y que pone en cuestionamiento permanente las historias oficiales a la luz del análisis de los documentos, las nuevas fuentes históricas que van surgiendo y las nuevas interpretaciones de los hechos y procesos históricos.

${ }^{8}$ Cfr. Le Goff, J., El orden de la memoria. El tiempo como imaginario, Barcelona, Ed. Paidós, 1991, p. 231.
} 
una primera definición recurrimos al Diccionario de la Real Académica de la Lengua Española encontremos hasta catorce acepciones diferentes dependiendo de la disciplina que la defina. Pero sin duda, la que la relaciona con la historia es el sentido que la define desde su carácter sicológico: "Facultad psíquica por medio de la cual se retiene y recuerda el pasado". En cuanto al término memoria colectiva hay que entenderlo como el conjunto de representaciones del pasado surgido en un grupo o sociedad, las cuales se van trasmitiendo de generación en generación por los miembros de ese grupo o sociedad; estas representaciones del pasado están constituidas por recuerdos. En este sentido, el recuerdo es la materia prima de la memoria, porque sin recuerdo no hay memoria. Para Peter Burke los recuerdos que conforman la memoria colectiva se trasmiten por cinco vías fundamentales:

1. Las tradiciones orales que dan a conocer de generación en generación las experiencias, expresiones culturales o acontecimientos significativos de un grupo.

2. Los recuerdos y escritos que nutren la memoria a través del registro de experiencias colectivas registradas en documentación escrita: se trata de recuerdos que son transformados a la hora de escribirse porque son redactados desde la memoria.

3. Las imágenes plasmadas a lo largo de la historia en lienzos, esculturas o fotografías, las cuales se han convertido en los mass media de la memoria colectiva.

4. Actos como rituales o conmemoraciones que sirven para mantener vivos y muy presentes los recuerdos de una comunidad.

5. El espacio, es decir, aquellos lugares emblemáticos vinculados a los recuerdos de un colectivo. ${ }^{9}$

El estudio histórico, sin duda, también se sirve de todas estas vías de transmisión de los recuerdos, no como proceso acumulativo con el que se elabora la memoria colectiva, sino a través del método crítico que los analiza, los contrasta y los cuestiona.

Cierto es que la memoria supone un elemento significativo de la historia: Marc Bloch consideraba la memoria como uno de los principales

${ }^{9}$ Cfr. Burke (2000), pp. 70-72. 
materiales de la historia, de hecho señala que "la civilización occidental siempre ha esperado mucho de su memoria. [Todo la lleva a hacerlo: tanto la herencia cristiana como la herencia antigua. Los griegos y los latinos, nuestros primeros maestros, eran pueblos historiográficos (... )]" (2001, p. 43). La escolástica en la época medieval la coloca como una de las potencialidades del alma. Santo Tomás distingue entre dos tipos de memoria: la sensitiva y la intelectiva. Las potencias sensitivas se refieren al cuerpo sensible, mientras que las potencias intelectivas refieren a lo inteligible o universal. Aristóteles consideraba la memoria, junto con la fantasía, como una de las pasiones de raíz sensitiva. ${ }^{10}$ Pero Santo Tomás matiza a Aristóteles situando a la memoria también en el plano intelectivo, ya que "el hombre no sólo tiene memoria como los demás animales por el recuerdo inmediato de lo pasado, sino que también tiene reminiscencia con la que analiza silogísticamente el recuerdo de lo pasado atendiendo a las intenciones individuales". ${ }^{11}$ Contrariamente a lo que sostiene San Agustín que entiende la memoria como facultad exclusiva de los sentidos y no del intelecto, Santo Tomás sostiene que

el hombre entiende ahora, ayer o mañana. $\mathrm{Y}$ esto no contradice su condición intelectual, puesto que entender, aunque sea algo particular, sin embargo, es un acto inmaterial, como dijimos al hablar del entendimiento. $\mathrm{Y}$ así, del mismo modo que el entendimiento se entiende a sí mismo aunque sea singular, también entiende su propio entender, que es un acto singular, tanto si se da en el presente como en el pasado o en el futuro. Así, pues, el concepto de memoria se salva en el entendimiento en cuanto referido a lo pasado, ya que entiende que entendió anteriormente. Pero no en cuanto que entienda lo pasado tal y como sucedió concretamente. ${ }^{12}$

Y ésta es la razón por la cual el hombre tiene historia y los animales no. Por ello, sólo se habla de memoria histórica para los hombres y sería un sinsentido referirse a la memoria "histórica" de los animales. De aquí, precisamente, ha provenido la idea de corresponder el concepto gnoseológico de memoria con la historia. Por ello, no es de extrañar que esta tradicional correspondencia o facultad atributiva de la historia tenga su continuidad en nuestros días incluso en los ámbitos menos

${ }^{10}$ Vid. Santo Tomás de Aquino, Suma Teológica, Parte 1a, Cuestión 78, Artículo 4, p. 718.

${ }^{11}$ Ibidem.

${ }^{12}$ Ibidem, Parte 1a, Cuestión, 79, Artículo 6, p. 730. 
académicos y más cotidianos: es habitual que escuchemos, cuando nos presentamos como historiadores los que nos dedicamos profesionalmente a la historia, el soniquete recurrente de "ah, pues debes tener mucha memoria”, como si los físicos, los médicos o los biólogos no trabajaran con la memoria y ésta fuera exclusiva de los historiadores. Mala cosa sería si un proctólogo no recordara cómo hacer el tacto rectal que aprendió en la facultad de medicina y terminara por olvido haciéndole a su paciente una auténtica caída del Imperio Romano. Conforme a ello, comparto la idea de Gustavo Bueno de considerar que el concepto de "Memoria histórica" tiene un carácter espurio:

Sobre todo cuando él pretende puede tener como referencia el supuesto (metafísico) "archivo indeleble" cuya custodia estaría encomendada al género humano; y que es susceptible de eclipsarse ante los individuos, dotados de una memoria más flaca. Por ello estos tendrán que "recuperar" una memoria histórica común, objetiva, que se supone ya organizada, aunque oculta (ocultada) a la espera de ser desvelada o recuperada. Por ello, la "recuperación de la memoria histórica" puede tomar la forma de una reivindicación: porque se supone que el eclipse de esa memoria histórica, que se sustenta en el seno del género humano, o en la sociedad, no es casual sino intencionado (2003, p. 3).

En los últimos años asistimos, pues, tanto en el mundo académico como en el social o político, cómo en muchos países se ha convertido la memoria histórica en un tema recurrente y recurrido en los debates históricos y políticos. Como afirma Todorov se podría sostener, sin equivocarse demasiado, que hay tres razones fundamentales por los que la memoria se ha convertido en un tema estrella de las discusiones actuales: en primer lugar, la necesidad de una identidad colectiva y, paralelamente, la necesidad contraria de destruir las identidades tradicionales; en segundo lugar, ocuparse del pasado en la actualidad tiene como beneficio añadido desentenderse de los problemas del presente, de tal manera que, el ocuparnos del pasado, nos generará un estado gratificador de buena conciencia, y, una última razón, es que aquellos que la practican se granjean un reconocimiento social del que se derivarán una serie de privilegios (2003, pp. 54-58).

Efectivamente, la memoria se ha convertido en casi un ejercicio de culto y comunión diaria, de tal manera que la memoria colectiva es en nuestros días un sinónimo de la llamada memoria histórica. En 1950 
se publica un libro del sociólogo francés Maurice Halbwach, asesinado por los nazis en un campo de concentración, La mémoire collective, ${ }^{13} \mathrm{el}$ cual va a convertir en un referente para la teorización de historiadores posteriores como Pierre Nora sobre este tenor. Halbwachs distinguía entre dos tipos de memoria, la personal o autobiográfica y la social o histórica (2004, p. 55). Consideraba, asimismo, que entre ambos tipos de memoria existe un gran contraste, ya que la memoria personal sólo representa el pasado de manera tangencial y se conoce desde dentro, mientras que la memoria colectiva tiene una mayor amplitud y se conoce desde fuera (ibídem). La memoria colectiva estaría compuesta por hechos del pasados que forman parte de nuestra memoria personal aunque no hayamos sido actores o testigos presenciales de los mismos, ya que igual se han podido leer en un periódico o se han escuchado directamente de personas implicadas en esos acontecimientos. Sin embargo, estos hechos históricos constituyen la memoria histórica de una sociedad. Halbwachs los entiende como nociones y símbolos, ya que

[... ] Una parte de mi personalidad está implicada en el grupo, de tal modo que nada de lo que se ha producido, en la medida en la que yo formo parte de él, me es completamente ajeno. Pero si quisiera reconstruir íntegramente el recuerdo de dicho acontecimiento, tendría que juntar todas las reproducciones deformadas y parciales de que es objeto entre todos los miembros del grupo (Ibidem).

Esta manera parcial de reunir recuerdos de la memoria colectiva, muchas veces inconexos y arbitrarios, no es el método con el cual opera la historia científica. Por lo tanto, el hecho de añadir al nombre de memoria el apellido de histórica no le concede el estatus de historia, entendido en su sentido científico. Y, aunque la memoria colectiva se baña en los hechos históricos, al ser incluidos de manera fragmentaria y subjetiva, desecha la idea de atribuir a la memoria histórica la consideración de historia.

Más reciente el historiador francés Pierre Nora ponía de "moda" la discusión acerca de la memoria histórica. Influido seguramente por el pensamiento histórico de Marc Bloch, el objetivo que se plateó Nora cuando dirigió la publicación en tres tomos de Les Lieux de mémoire

${ }^{13}$ Vid. traducción al español La memoria colectiva, Prensas Universitarias de Zaragoza, Zaragoza, 2004. 
(1984-1993) fue entender nuestro presente a través del pasado. En dicho libro Nora, sin sentar una oposición radical entre memoria e historia, sí las distingue como cosas diferentes, destacando la relación existen entre memoria y presente.

Nora considera que historia y memoria, más que ser conceptos sinónimos, son términos opuestos. Para argumentar esta oposición establece varias diferencias entre ambas categorías:

1. La memoria es la vida y está abierta tanto al recuerdo como al olvido colectivo, por lo que está sujeta a las deformaciones. Por su parte, la historia supone una reconstrucción de una realidad que ya no existe.

2. La memoria siempre está ligada al presente. La historia es una representación del pasado.

3. La memoria, al tener un carácter afectivo y mágico, está constituida de fragmentos que la reconfortan que se nutren de recuerdos vagos, particulares o simbólicos. En cambio, la historia, al tener un carácter intelectual y laico, se desarrolla a través de análisis y discurso crítico.

4. La naturaleza de la memoria es múltiple, desmultiplicable, colectiva plural e individualizable, por lo que existirán tantas memorias como grupos sociales. Sin embargo, la historia pertenece a todos y a nadie, por lo que su vocación siempre es universal.

5. Frente a la memoria que se origina en lo concreto, el espacio, el gesto, la imagen y el objeto, la historia está ligada a las continuidades y las evoluciones temporales, así como a las relaciones entre las cosas.

6. Finalmente, la memoria es un absoluto mientras que la historia sólo conoce lo relativo. ${ }^{14}$

Según esto se destacaría que memoria e historia no sólo son categorías definitivamente disímiles, sino que operan en planos diferentes.

14 "Entre memoria e Historia: La problemática de los lugares". En Nora, P. (dir.), Les Lieux de mémoire, vol. I, Gallimard, Paris, 1984, pp. xvII-xLIL, cfr. http://comisionporlamemoria.org/bibliografia_web/historia/Pierre.pdf. 
En fin, la memoria "histórica" está sujeta constantemente a mutaciones o cambios arbitrarios basados en arranques emotivos. Sin embargo, la historia supone un ejercicio de racionalidad crítica que se apoya en datos empíricos del pasado, los cuales son analizados mediante los métodos de la historia. Esta oposición u oposiciones existentes entre ambas convierten, como veremos más adelante, a la historia en la mano ejecutora de la destrucción de la memoria "histórica" -parcial y selectiva que no respeta el pasado- desde el momento en que su relato se construye desde el rigor científico. Por ello, el rigor histórico es incompatible con la creación de "historias" que terminen constituyendo una memoria colectiva común muchas veces auspiciadas o elaboradas ad hoc con fines muy concretos desde el poder.

\section{La creación de la memoria desde narrativas del poder}

Es ya un lugar común la frase que dijo Voltaire de "la historia la escriben los vencedores". Vista así, cualquiera puede tener la sensación de que la historia es radicalmente parcial y selectiva de los acontecimientos. Sin embargo, efectivamente, el poder siempre ha puesto sus manos sobre el pasado y ha tenido que ver en la escritura o en la manipulación de la historia para la creación de historias oficiales. Tradicionalmente la historia dominante ha sido la escrita desde el poder, anclada en un pasado solidificado por la realidad objetiva de las batallas, los grandes jerarcas de la política o la religión y apoyada en un cierto fetichismo de los documentos escritos. Y es que, como sentenciaba George Orwell en 1984, aquel que "controla el pasado controla el futuro", pero además "el que controla el presente controla el pasado", añadía. De ahí la relevancia que se ha dispensado tradicionalmente a la historia desde el poder político o desde los aspirantes a ese poder político, por ejemplo, a partir de la ideología nacionalista. La historia desde tiempos inmemoriales ha sido convenientemente manipulada desde el poder. La razón estriba en que cualquier ideología que aspira a alcanzar el poder político necesita "alterar" el pasado, ya que ello le permite extraer unas conclusiones ex profeso sobre el mismo que justifiquen sus aspiraciones de presidir, tutelar o administrar la sociedad del futuro. Esta historia fabricada desde el poder, en casos como la construcción de identidades nacionales, constituyó un terreno fértil donde sembrar una memoria colectiva revelada. En este sentido, la 
historia es origen y finalidad del nacionalismo, el pasado es fácilmente maleable si no responde a las necesidades de la nación, por lo que si no existe un pasado adecuado, siempre se puede inventar uno nuevo que satisfaga las necesidades identitarias. No por nada Leopold Ranke afirmó en el siglo xix que para ser nación lo único que se necesitaba era interpretar la historia de manera equivocada. La historia científica no construye identidades, no es esa su función, pero la preocupación compulsiva por la utilización de la historia con fines ajenos a la misma la han llevado a su manipulación.

En nuestros días, en un mundo sustentado en las bases del pragmatismo, el valor y la función de la historia pareciera que está relegado a un papel "secundario" dentro de nuestra sociedad, pero esto no es así como vamos a ver. Los historiadores día sí y día también somos cuestionados con preguntas del tenor de "para qué sirve la historia". Más allá de la incomodidad que pueda ocasionar este tipo de preguntas, que observaría Marc Bloch, lo que denotan es un evidente desconocimiento de la función de la historia y, por lo tanto, de su valor intrínseco y de su sentido social. Su valor pragmático no es tan evidente como el de otras ciencias o disciplinas del saber y eso la pone en un cuestionamiento sistemático desde la sociedad. La prueba la tenemos en que difícilmente encontraremos a alguien que se le ocurra preguntar por la relevancia o pertinencia de la medicina o de la ingeniería -lo cual sería absurdo- pero de la historia, sí. Ahora bien, si nos damos cuenta, al preguntar para qué sirve la historia lo que se está suscitando es una auténtica querella acerca de su legitimidad. Esta situación ha sido en parte generada por los propios historiadores que no hemos sabido "popularizarla" desde el rigor de los estudios históricos y extender su conocimiento a toda la sociedad. Esta incapacidad para promocionar la historia desde el rigor académico ha ocasionado que el espacio público de la historia sea ocupado por una suerte de revelación sucedánea de memoria "histórica", más inmediata, impactante y que puede llegar a ofrecer mayores réditos políticos. Esto hace que, la historia y el trabajo del historiador, en determinados contextos se vaya a considerar como fundamental: aquí es donde observamos las importantes propiedades balsámicas sociales y políticas que desde el poder político se le conceden. Sin embargo, esta espuria valoración de la historia se contradice con los criterios profesionales de los historia- 
dores. Ello es así porque se opone al rigor histórico y a la investigación de la historia, subordinándola al servicio de la política o de los compromisos ideológicos, lo cual sitúa a la historia en las antípodas de la ciencia. El problema de algunos historiadores es que son sensibles o insensibles a ciertos hechos, análisis o interpretaciones, lo cual no les permite la posibilidad de separar al observador de la cosa observada y a la Historia del historiador, que diría Paul Valery.

Desgraciadamente, en la actualidad se está dando una lamentable actitud de desenterrar las reliquias del pasado para judicializar la historia, manipulándola para adecuarla a unas circunstancias o contexto político actuales. Una demostración de ello lo ejemplariza un simposio celebrado en diciembre de 2013 titulado "Espanya contra Catalunya: una mirada històrica (1714-2014)", promovido por el Institut d'Estudis Catalans de Barcelona y organizado por el Centro de Historia Contemporánea, institución vinculada al Departamento de Presidencia de la Generalitat de Cataluña. El poder político, que gestiona becas y subvenciona con dinero público la investigación, urge en este contexto de necesidades identitarias a la recuperación de la tradición, real o ficticia, a través de la escritura de una memoria colectiva manufacturada. Acertadamente señalaba Hobsbawm (1988) que la tradición no es otra cosa que "un conjunto de prácticas regidas por reglas manifiestas o aceptadas tácitamente y de naturaleza ritual o simbólica, que buscan inculcar ciertos valores y normas de comportamiento por medio de la repetición. Es esencialmente un proceso de formalización y de ritualización que se caracteriza por su referencia al pasado, aunque sólo sea por una repetición impuesta". Por ejemplo, seudohistoriadores manipulan el origen de personajes destacados de la historia, ${ }^{15}$ o que se inventen hechos que nunca sucedieron para adaptarlos a la realidad de la construcción nacional. ${ }^{16}$

${ }^{15}$ De esta forma, el gran humanista valenciano Juan Luis Vives por arte de la distorsión interesada pasa a llamarse Joan Lluís Vives y ser catalán. Vid. Jordi Segarra, "L'hecatombe de la família d'En Joan Lluís Vives”, en Instut Nova Historia, 4 de Diciembre de 2017, https:/wwww.inh.cat/articles/L-hecatombe-de-la-familia-d-En-Joan-Lluis-Vives.

${ }^{16}$ Así sucede con el libro de Jordi Bilbeny, El dit d'en Colom: Catalunya, l'Imperi i la primera colonització americana (1492-1520), Col-lecció Descoberta Libre D'índex, 2010, en el que se afirma no sólo la falsedad, sino el anacronismo histórico de que Colón fue embajador de la Generalitat de Cataluña. Aunado a esto, en una entrevista que le realizó el periódico digital 20minutos en 2010 ya había ofrecido manifestaciones delirantes como que "Cervantes lo escribió -se refiere al Quijote-, pero en catalán. Él era catalán. A los autores de los siglos xvi y xviı les obli- 
En este ambiente político, la creación de condiciones ideológicas para generar la imposición de una identidad y el establecimiento de relaciones de poder y sometimiento dificultan la neutralidad historica. Esta neutralidad se sustituye por un memoria elaborada a través de una imagen distorisionada del pasado y una manipulación de nuestro presente. Y, es que, recurrir al pasado en determinados contextos es especialmente rentable, ya que permite crear las condiciones oportunas de sensibilidad y conciencia necesaria para elaborar un clima identitario al que sumar más adeptos.

Hacer una historia de los agravios, como planteó este simposio, es de por sí manipulador, porque la historia no es absoluta, la historia requiere de que se expliquen sus matices y realidades objetivas, necesarios para acercarnos lo más posible a la verdad histórica. Dice Todorov en Los abusos de la memoria que conmemorar las víctimas del pasado es sumamente gratificador. Esto es evidente en el caso del nacionalismo catalán, quien está manejado deliberadamente la historia para construir memorias identitarias basadas en falsos agravios del pasado. Estas memorias construidas a través de la manipulación de la verdad histórica y promocionadas desde el poder político y su propósito se explica en un doble sentido: porque desvía la atención de los problemas reales y porque, como con acierto afirma Todorov, "ese recuerdo les permite olvidar -eso esperan- las agresiones por las que se convierten ahora en culpables; y no son lo únicos en actuar de ese modo" (2013, p. 56). La realidad de la historia es más compleja y cambiante que un enunciado como el de "España contra Cataluña", que presupone que desde 1714 hasta la actualidad ha existido un enfrentamiento continuo de identidades. Ello, desde el punto de vista histórico es tan falso, como establecer que los catalanes, los occitanos o los sardos del siglo xviII, su cosmovisión, su realidad material o sus circunstancias son las mismas que las de los catalanes, occitanos o sardos del siglo xxi. La historia escrita desde el rigor científico supone la antítesis del mito y la deformación interesada del pasado, como vamos a ver.

garon a traducir su obra al castellano, por una obligación del Rey[... ]" o que Santa Teresa de Jesús también era catalana pero lo que se había producido era un "historicidio o genocidio cultural" contra los catalanes. Vid. http://www.20minutos.es/noticia/1894569/0/entrevistajordi-bilbeny/cervantes-era-catalan/escribio-quijote-catalan/. 


\section{La destrucción de la memoria}

Uno de los problemas que deslegitiman la "epistemología" de la memoria "histórica" - desde el punto de vista de la ciencia- es que cuando se construye la memoria colectiva, a diferencia de la historia, se establece qué hechos se deben recordar y cuáles se deben olvidar, lo cual nos sitúa en un escenario de ejercicio de radical subjetivismo. Es decir, la existencia de memoria implica la existencia lógica de amnesia. Por este motivo, la existencia de memoria "histórica" involucraría no sólo la existencia del olvido, sino que necesitaría de éste para constituirse como tal: si existen hechos que se recuerdan, también les hay que se olvidan.

Cada grupo, cada pueblo tiene su halakhah, pues la halakhah no es la ley, nomos. La palabra hebrea que significa "marchar", halakh es por lo tanto el camino por el que se marcha, el Camino, la Vía, el Tao, ese conjunto de ritos y creencias que da a un pueblo el sentido de su identidad y de su destino. Del pasado sólo se transmiten los episodios que se juzgan ejemplares o edificantes para la halakhah de un pueblo tal como se la vive en el presente. El resto de la "historia" -arriesguemos la imagen - va a dar a la zanja (Yerushalmi, 1989).

Ahora bien, memoria y amnesia son aspectos sicológicos que tienen que ver no con la colectividad, sino con la individualidad, aunque pueden ser asimilables o transferibles a la colectividad. Por otra parte, la memoria "histórica" individual siempre será parcial y limitada en el tiempo: yo no puedo tener memoria de la civilización maya porque la memoria se reconstruye a partir de experiencias personales vividas o mediante aquellas experiencias que consideramos personales pero vividas por nuestros antepasados más inmediatos.

Frente a ello, la historia se construye a partir de unas reglas claras y consensuadas por el colectivo de historiadores sustentadas en el método científico. La historia que se procesa, y que se rescribe cada generación de historiadores conforme a las nuevas evidencias que se descubren, no tiene mucho que ver con la memoria histórica: la Historia, como bien observa Gustavo Bueno, supone una reconstrucción, interpretación y ordenación crítica de evidencias físicas que permanecen en el presente. Por su parte, la memoria histórica tiene un carácter parcial, episódico y nos remite 
a un sujeto abstracto (la Sociedad, la Humanidad, una especie de divinidad que todo lo conserva y lo mantiene presente) capaz de conservar en su seno la totalidad del pretérito que los mortales del presente deben descubrir. Esta memoria histórica tiende a ser una memoria histórica total, que se aproxima a lo que pudiera ser la memoria eterna de quien vive las cosas tota simul et perfecta possesio. Pero este sujeto abstracto, receptáculo de la memoria histórica no existe, es un sujeto metafísico. No hay "memoria histórica" (Bueno 2003, p. 2).

Es por eso que afirmamos que la historia supone la destrucción de la memoria histórica en el sentido sicológico, porque convierte las memorias selectivas de grupo en memorias universales, pero a su vez:

La memoria histórica es a la vez damnatio memoriae. Por ejemplo, la memoria histórica, que contradictoriamente, propone borrar un retrato de Girón, ministro de Franco, de la Universidad Laboral de Gijón. Que propone retirar del callejero de una ciudad los nombres de los "golpistas" que se alzaron contra la República; una memoria histórica que por otra parte no pide eliminar los nombres de otros golpistas contra la República, los de octubre de 1934, como lo fueron Ramón González Peña o Belarmino Tomás (ibidem, p. 3).

De tal manera, que cuando estamos hablando de hechos o acontecimientos todavía muy presentes en la memoria, depende mucho de quién los cuente y cómo los cuente. Con ello me refiero a que las versiones serán distintas entre los propios actores o testigos de los hechos, pero también será diferente entre aquellos que estuvieron implicados en estos acontecimientos y los que no lo estuvieron. Esto último demostraría otra certeza: que la visión de hoy será también diferente a la de mañana. Por ello, la disciplina histórica exige renunciar a la tendencia actual, especialmente en los asuntos de "memoria e historia, amnesia y amnistía”, de judicializar la historia, que es lo que muchas veces se hace a través de la recuperación de la memoria histórica. La historia como ciencia no juzga a nadie, ni siquiera debe juzgar, para eso está la carrera judicial. Contra la idea de definir claramente quién fue el culpable y quién la víctima, el historiador no puede determinar la intencionalidad. Obedecer a la "demanda social" sería convertir al historiador en un instrumento, en un servidor del consumo cultural de la memoria, y esa no es su función: la historia no es una oNG. 
Vemos, pues, que los fines que persiguen memoria e historia son diametralmente distintos, porque mientras la historia busca la verdad, la memoria atiende a la fidelidad (Erice 2009, p. 78). Por lo tanto, no es lo mismo construir la memoria que hacer la historia, así como no toda memoria es resultado de la historia ni la historia es memoria. La historia es obra del entendimiento, no de la memoria. Por lo tanto, si el historiador se quiere acercar a la verdad tendrá necesariamente que llevar a cabo un ejercicio de destrucción de estas memorias. Porque que al fin y al cabo la labor del historiador como decía Febvre, consiste en "hacer historia, enseñar historia: remover cenizas, unas ya frías y otras todavía tibias, pero siempre cenizas, residuos inertes de existencias consumidas" (1982, p. 26). Finalmente, podemos llegar a la conclusión de que la historia, como antimemoria, supone el antídoto adecuado contra el subjetivismo radical y la parcialidad de las memorias históricas. De ahí la necesidad de mirar hacia la historiografía científica que, sustentada en la deontología del contraste de los hechos mediante el método científico, busca siempre la verdad histórica ajena a las manipulaciones ideológicas o de los recuerdos colectivos seleccionados.

\section{Referencias}

Agencia Estatal, 2007, "Ley 52/2007, de 26 de diciembre, por la que se reconocen y amplían derechos y se establecen medidas en favor de quienes padecieron persecución o violencia durante la guerra civil y la dictadura”, en Boletín Oficial del Estado (27 de diciembre de 2007).

Bloch, M., 2001, Apología para la historia o el oficio de historiador, Fondo de Cultura Económica, México.

Bueno, G., 2003, "Sobre el concepto de 'memoria histórica común"', en $E l$ Catoblepas, no 11, pp. 2-5.

Burke, P., 2000, Formas de Historia Cultural, Alianza Editorial, Madrid.

Erice, F., 2009, Guerras de la memoria y fantasmas del pasado. Usos y abusos de la memoria colectiva, Eikasia, Oviedo.

Febvre, L., 1982, Combates por la historia, Seix Barral, Barcelona.

Halbwach, M., 2004, La memoria colectiva, Prensas Universitarias de Zaragoza, Zaragoza.

Hobsbawm, E. 1988, "Inventando tradiciones”, Historias no. 19, México, pp. 3-15.

Le Goff, J., 1991, El orden de la memoria. El tiempo como imaginario, Editorial Paidós, Barcelona. 
Santo Tomás de Aquino, 2011, Suma Teológica, Biblioteca de Autores Cristianos, Madrid, Parte 1a.

Sartre, J.P., 1948, Reflexiones sobre la cuestión judía, Ediciones Sur, Buenos Aires. Todorov, T., 1993, Las morales de la historia, Editorial Paidós, Barcelona.

—, 2013, Los abusos de la memoria, Editorial Paidós, Barcelona.

Yerushalmi, Y. et al., 1989, Los usos del olvido, Nueva Visión, Buenos Aires.

Yerushalmi, Y., 1989, "Reflexiones sobre el olvido", en Yerushalmi et al. 1989, pp. 13-26. 